\title{
CLIMATE CHANGE AND FOOD SECURITY OF THE MALAYSIAN EAST COAST POOR: A PATH MODELING APPROACH
}

\author{
Md. Mahmudul Alam* \\ School of Economics, Finance \& Banking (SEFB), College of Business (COB), \\ Universiti Utara Malaysia (UUM), Sintok, Malaysia \\ E-mail: rony000@gmail.com \\ Tel: +601 82467050 \\ Basri Abdul Talib \\ Associate Professor \\ Faculty of Economics and Management \\ National University of Malaysia (UKM) \\ 43600 UKM Bangi, Selangor Darul Ehsan, Malaysia \\ E-mail: basri@ukm.my \\ Chamhuri Siwar \\ Emeritus Professor \\ Institute for Environment and Development (LESTARI) \\ National University of Malaysia (UKM) \\ 43600 UKM Bangi, Selangor Darul Ehsan, Malaysia \\ E-mail: csiwar@ukm.my \\ Abu N.M. Wahid \\ Managing Editor, the Journal of Developing Areas \\ Professor, Department of Economics and Finance \\ Tennessee State University \\ Nashville, Tennessee, USA \\ E-mail: awahid@tnstate.edu \\ Tel: +615-963-7149 \\ * Corresponding author
}

Citation Reference:

Alam, M.M., Talib, B., Siwar, C., and Wahid, A.N.M. 2016. Climate Change and Food Security of the Malayan East Coast Poor: A Path Modeling Approach. Journal of Economic Studies, Vol. 43(3), pp. 458 - 474. [Online Link]

This is a pre-publication copy.

The published article is copyrighted by the publisher of the journal. 


\title{
CLIMATE CHANGE AND FOOD SECURITY OF THE MALAYSIAN EAST COAST POOR: A PATH MODELING APPROACH
}

\begin{abstract}
This research aims at examining the direct and indirect impacts of climatic changes as well as the effects of non-climatic factors on household food security in Malaysia. The study is based on primary data collected in the months of July - October, 2012 through a questionnaire survey on 460 low income households from East Coast Economic Region (ECER) of the country. The samples were selected from E-Kasih poor household database, based on cluster random sampling technique. The statistical estimation was done through two-stage formative path measurement model by using nonparametric bootstrap procedure under Smart PLS. This study finds that household food insecurity ECER - Malaysia is not only related to social and economic factors, but also statistically significantly linked to the direct and indirect impacts of climatic factors. The policy implications of the study suggest that design of food security programs must be integrated with climatic change adaptation programs. The government and other relevant agencies should jointly develop appropriate policies for poverty alleviation, household level food security, and adaptation with climatic changes in Malaysia.
\end{abstract}

JEL Classifications: I32, Q54, P48

Keywords: Climatic Changes, Household Food Security, Path Modeling, Bootstrap Method, Malaysia, East Coast Economic Region

\section{Introduction}

Food security is a burning issue and of great concern for many nations on the face of the earth. At national level, the adequacy of domestic food production or capability to mobilize food on time from international market may be sufficient. However, it does not automatically guarantee sustained food security at household level. The factors determining food security at household level are more crucial than those at national level.

There are several factors that are attributable to household food insecurity in Malaysia. They include political, economic, environmental, social, infrastructural, health related issues, (Lovendal and Knowles 2006). Some put emphasis on income distribution and income inequality in communities (Frankenberger 1992). Others believe that it depends on physical, natural, human resources, and availability of technology in the area (Nyariki and Wiggins 1997). Yet another group thinks that it is household's demography and education that are important. (Iram and Butt 2004). ECA study (2004) suggests that land, land tenure system, and farmers' productively are important (Cristofar and Basiotis: 1992). Olson et al. (1997); and Rose et al. (1995) find that women's education and their income-earning capability are important for household level food insecurity in question.

Changes in the climatic factors and their outcomes, such as natural calamities may also worsen household food insecurity. In the Intergovernmental Panel on Climate Change (IPCC 2007), the Fourth Assessment Report recorded that food security and malnutrition may be severely affected by climate change and its variability. There are four dimensions of food security such as availability of food, stability of its supply, accessibility to food, and utilization of food. All of them may be affected by climate change (FAO 2008). The effects of climate change mainly have negative impacts on nutrition and food security (FAO 2007). Water scarcity and droughts reduce the nutritional diversity and decrease the general food consumption which would cause malnutrition such as micronutrient deficiencies, proteinenergy malnutrition, and under nutrition (IPCC 2007). The increase in rainfall, temperature, 
sea levels, salinity, etc. also give rise to human settlement areas being flooded (Cruz et al. 2007; Mimura et al. 2007), scarcity of freshwater (Kundzewicz et al. 2007), increase diarrhea and other contagious diseases (Checkley et al. 2000; Kovats et al. 2004; Zimmerman et al. 2007). Climatic changes also have impacts on food distribution, influencing people's access to markets to sell or purchase food (Abdulai and CroleRees 2001), increase food prices (Cline 2007; von Braun 2007), and reduce real income (Thomsen and Metz 1998).

Malaysia is a very fast growing developing country, but it never reached selfsufficiency in food. Moreover, the climatic factors are changing very rapidly in Malaysia and have been having adverse impacts on food production. In the case of Malaysia, carbon dioxide $\left(\mathrm{CO}_{2}\right)$ emissions have increased by $221 \%$ during the period of 1990 - 2004 (EIA 2005) and is included in the list of 30 biggest greenhouse gas emitters. Curb Global Warming (2007) notes that in spite of the rapid growth in emissions, Malaysia has ratified the Kyoto Protocol and has taken several initiatives to use renewable energy as well as ways to cut emissions. Malaysia is the 26th largest greenhouse gas emitter in the world. Due to high greenhouse gas emissions, the temperature is projected to rise by $0.3-4.5^{\circ} \mathrm{C}$ in near future.

Warmer temperature is likely to cause the sea level to rise by about $95 \mathrm{~cm}$ over a hundred-year period. The changes in rainfall may fluctuate from $-30 \%$ to $+30 \%$. It may reduce crop yield and cause drought in many areas so that cultivation of some crops may not be possible (MOSTE 2001). Moreover, the recent projection shows maximum monthly precipitation, which may increase up to $51 \%$ over Pahang, Kelantan, and Terengganu, while minimum precipitation is likely to decrease between $32 \%$ and $61 \%$ for the whole of Peninsular Malaysia. Consequently, annual rainfall may increase up to $10 \%$ in Kelantan, Terengganu, Pahang, and North West Coast, and decrease up to 5\% in Selangor and Johor (NAHRIM 2006). Tisdell (1996) finds that rainfall variability increases the level of environmental stress that affects the capability of the system to maintain productivity.

Under the current climate change scenario, temperatures above $25^{\circ} \mathrm{C}$ may decline grain mass at $4.4 \%$ per $1{ }^{\circ} \mathrm{C}$ rise (Tashiro and Wardlaw 1989), and grain yield may decline as much as $9.6 \%$ to $10.0 \%$ per $1{ }^{\circ} \mathrm{C}$ rise (Baker and Allen 1993), whereas the average temperature in rice growing areas in Malaysia is about $26^{\circ} \mathrm{C}$. Singh et al. (1996) reveal that the actual farm yield of rice in Malaysia vary from 3 to 5 tons per hectare, where potential yield is 7.2 tons per hectare. The study also reveals that there is a decline in rice yield between $4.6 \%$ and $6.1 \%$ per $1{ }^{\circ} \mathrm{C}$ temperature increase and that doubling of $\mathrm{CO}_{2}$ concentration (from present level of $340 \mathrm{ppm}$ to $680 \mathrm{ppm}$ ) may offset the detrimental effects of $4^{\circ} \mathrm{C}$ temperature increase on rice production in Malaysia. Overall, based on the analysis of minimum and maximum yield of the last 28 years, the macro cases of the national data from 1980 to 2008 of Malaysia show that the yield of paddy would decrease between $43 \%$ and $61 \%$ if there is a $1{ }^{\circ} \mathrm{C}$ temperature and 1 millimeter $(\mathrm{mm})$ rainfall increase (Ali and Ali 2009). In a recent study, based on the micro data on paddy field of Integrated Agricultural Development Area (IADA), North-West Selangor, it was found that a $1 \%$ increase in temperature might lead to $3.44 \%$ decrease in current paddy yield and $0.03 \%$ decrease in paddy yield in the next season. In addition, a $1 \%$ increase in rainfall might lead to $0.12 \%$ decrease in current paddy yield and $0.21 \%$ decrease of paddy yield in the next season (Alam et al. 2014). Projection reveals that any changes, both positive and negative, by more than only $0.4 \%$ may cause the yield of paddy production in Malaysia to fall (MOSTE 2001).

It is widely held that climate change is one of the major potential threats to national food security in Malaysia. Thus, to adopt proper policy options and achieve food security in Malaysia, it is very important to study the current situation of household food security and its possible linkage with the changes in climatic factors. Hardly any work has been done on the impacts of climate change at the household level food security in Malaysia. Therefore, we make this attempt to study and analyze the problem in an in-depth manner. The findings of 
the study are expected to give inputs to the Malaysian planners in formulating appropriate policies achieving Vision 2020. This vision includes the targets of food security, socioeconomic betterment, and poverty alleviation at the grass-root level. Moreover, this study may help policy people to develop comprehensive strategy to reduce the vulnerability of sustainable livelihood in both urban and rural Malaysia.

\section{Data, Model, and Methodology}

\section{Data Collection}

Data for this study were collected through an extensive questionnaire survey at household level in East Coast Economic Region (ECER) in Malaysia. ECER is more than half of the Peninsular Malaysia with the area of about $66,000 \mathrm{sq} \mathrm{km}$ that covers the states Kelantan, Terengganu, Pahang, and Mersing in Johor. ECER is very crucial for two major reasons; (a) ECER is the most vulnerable area in Malaysia due to climatic changes and (b) the income level of this region is low and poverty rate is high that is an obstacle to achieve Vision 2020.

This study is based on primary data collected from 460 households in the urban and rural areas of ECER. The urban area of Kuantan and rural area of Pekan were selected from Pahang state. The urban area of Kota Bharu and rural area of Tumpat were chosen from Kelantan state. The urban area of Kuala Terengganu and rural area of Maring were taken from Terengganu state. A questionnaire guide technique was used to collect data. The survey was conducted by the regular enumerators of the Implementation Coordination Unit (ICU) from Pahang, Kelantan, and Terengganu states in the months of July - October, 2012. The survey followed the cluster random sampling technique. Initially the samples were clustered by location and then by poverty category. Finally, from each category, samples were picked up randomly from the E-Kasih database. E-Kasih system has been an integrated database system that has enlisted poor households at the national level to plan, implement, and monitor poverty programs in Malaysia.

\section{Estimation of the Household Food Security: A Path Modeling Approach}

To estimate the influence of climatic, non-climatic, and demographic factors on the level of household food security of the study area, path measurement modeling has been used. In the estimation of path modeling, individual dimensions of food security are not observable per se, and are considered as a latent variable depending on the terms on several climatic, demographic, and non-climatic general factors observed variables. In the causal models literature (Spirtes et al. 2000), circles represent latent variables and boxes represent observed variables. Most of the hierarchical or multi-level models studied in the literature deal with measured variables, thus, the regression properties are extended. One of the innovative contributions of this research is the estimation of latent variable models in complex survey data.

Structural equation models (SEMs) are the most appropriate tools for dealing with this kind of model. This study uses Smart PLS that relies on a nonparametric bootstrap procedure to test coefficients for their significance. The PLS path modeling method clearly has some advantages over other common modeling conditions that present challenges with covariancebased methods. The advantages include non-normal data, smaller sample sizes, formative indicators, etc. It is called the variance based structural equation modeling that can be regarded as a multivariate extension of the ordinary least squares (OLS) regression. The iterative algorithm conducted in PLS consists generally of a series of OLS analyses (Chin 1998). 
PLS path modeling methodology allows reflective and formative computations with respect to the measurement of latent variables. Formative measurement models come into use when an explanatory combination of indicator variables underlies the latent construct which can best be used when the items describe and define the construct rather than vice versa (Diamantopoulos 2006; Petter et al. 2007). In a formative measurement model, indicators represent the latent construct's (potentially) independent causes and thus do not necessarily have high correlation. Furthermore, formative indicators are assumed to be error free (Edwards and Bagozzi 2000). While developing the path modeling, this study followed the formative measurement model. This estimation used a two-stage formative measurement model (Figure 1). Similar type of measurement model was also used by Alinovi et al. (2009, 2010).

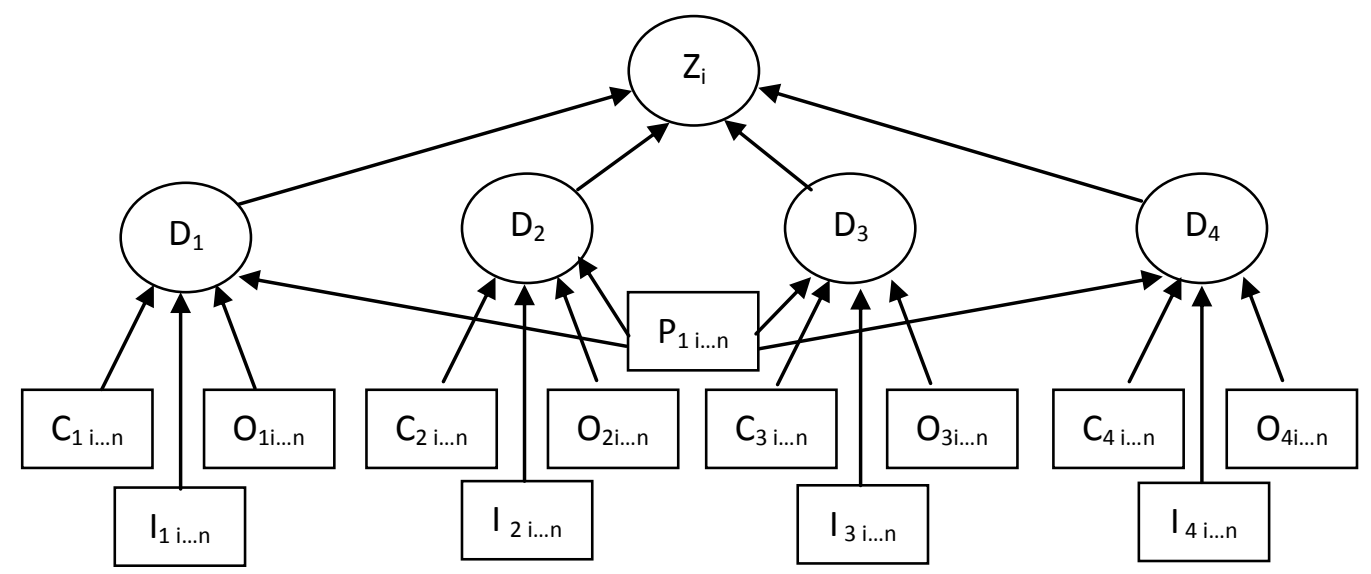

Figure 1: Path Diagram of the Household Food Security Model

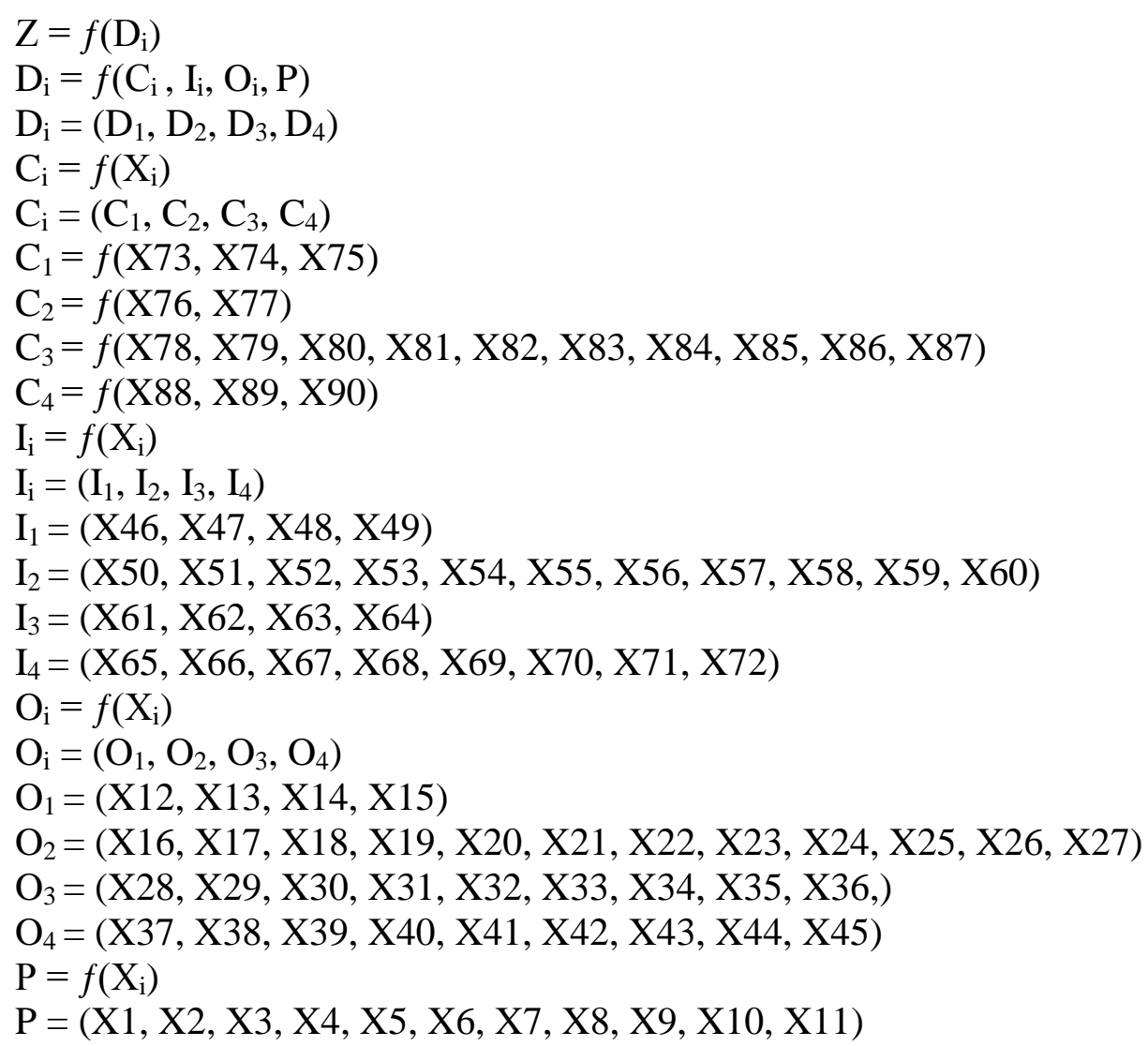


For definition of the variables, please see the Appendix

\section{Estimation of the Household Food Security: A Path Modeling Approach}

To determine the influence of climatic and non-climatic general factors on the level of household food security in Malaysia, the study conducted bootstrap procedures for $2^{\text {nd }}$ stage formative measurements path modeling. In the initial model, only six variables have been found insignificant, whereas, both the weight and loading of these indicators are smaller than the critical $t$-values (1.65) for a two-tailed test, even at $10 \%$ significance level. These insignificant indicators are locality (X7), spouse doing job (X4), head of household having supplementary job (X5), earning ratio (X6), and household poverty/economic status (X3) under the resilience factors (P1) that have linkage with all four dimensions of household food security. Another indicator is current prices of general food items (X17) under the nonclimatic general factors $(\mathrm{O} 2)$ of food accessibility dimension.

For the validity of the model, it is assumed that when the loading and weight are nonsignificant, no empirical support to retain the indicator in the model is available (Cenfetelli and Bassellier 2009). However, it is also empirically suggested not to remove the indicators from the model while carrying out the model for formative measurement The reason is that removing the items would indicate missing an essential portion of the nomological domain of the constructs and disrupting the content validity (Bollen and Lennox 1991). Excluding these variables, normally has nearly no effect on the parameter projections when re-estimating the model. Removing formative indicators may cause consequences that are adverse for the measure's content validity (Diamantopoulos and Siguaw 2006). Therefore, this study further tests the model by omitting these variables to decide whether to retain or delete these nonsignificant indicators.

The revised model shows that due to omitting these important variables, the overall resilience construct (P1) is insignificant to all of the four dimensions of household food security (Table 2; Figure 3). Thus, these indicators are theoretically very important to determine the level of household food security. In this model, only six factors are insignificant out of a total of 91 factors. Previous studies also noticed that the more indicators were used to calculate a formative latent construct, the higher the tendency that one or more of the indicators would reveal low or non-significant weightage. In that case, researchers suggested placing the indicators into groups of two or more unique constructs, if there was theoretical support for this procedure (Cenfetelli and Bassellier 2009). Since this research is based on the second stage, it has grouped the entire resilience factors into a single construct. Thus, this study considers that the initial model is better than the revised model, and, therefore, here the initial model is considered to draw the inferences.

Table 1: Path Coefficient and Total Effect of Path Modeling

\begin{tabular}{lccccc}
\hline Path Direction & $\begin{array}{c}\text { Original } \\
\text { Sample } \\
(\mathbf{O})\end{array}$ & $\begin{array}{c}\text { Sample } \\
\text { Mean (M) }\end{array}$ & $\begin{array}{c}\text { Standard } \\
\text { Deviation } \\
\text { (STDEV) }\end{array}$ & $\begin{array}{c}\text { Standard } \\
\text { Error } \\
(\text { STERR) }\end{array}$ & $\begin{array}{c}\text { T Statistics } \\
(\mid \mathbf{O S T E R R | )}\end{array}$ \\
\hline C1->D1 & $0.3590^{*}$ & 0.3499 & 0.0376 & 0.0376 & 9.5581 \\
C1->Z & $0.0678^{*}$ & 0.0649 & 0.0090 & 0.0090 & 7.5741 \\
C2->D2 & $0.0938^{*}$ & 0.0902 & 0.0132 & 0.0132 & 7.1117 \\
C2->Z & $0.0365^{*}$ & 0.0349 & 0.0045 & 0.0045 & 8.0901 \\
C3->D3 & $0.7065^{*}$ & 0.6832 & 0.0435 & 0.0435 & 16.2245 \\
C3->Z & $0.1565^{*}$ & 0.1528 & 0.0191 & 0.0191 & 8.2068 \\
C4->D4 & $0.1724^{*}$ & 0.1676 & 0.0195 & 0.0195 & 8.8311 \\
C4->Z & $0.0551^{*}$ & 0.0534 & 0.0063 & 0.0063 & 8.7023
\end{tabular}




\begin{tabular}{|c|c|c|c|c|c|}
\hline D1->Z & $0.1888 *$ & 0.1853 & 0.0133 & 0.0133 & 14.2127 \\
\hline D2->Z & $0.3891 *$ & 0.3882 & 0.0223 & 0.0223 & 17.4796 \\
\hline D3->Z & $0.2215 *$ & 0.2232 & 0.0187 & 0.0187 & 11.8619 \\
\hline D4->Z & $0.3197 *$ & 0.3191 & 0.0169 & 0.0169 & 18.8721 \\
\hline I1->D1 & $0.6839 *$ & 0.6764 & 0.0579 & 0.0579 & 11.8018 \\
\hline I1->Z & $0.1291 *$ & 0.1251 & 0.0114 & 0.0114 & 11.313 \\
\hline I2->D2 & $0.8311 *$ & 0.8235 & 0.0308 & 0.0308 & 26.9859 \\
\hline I2->Z & $0.3234 *$ & 0.3199 & 0.0249 & 0.0249 & 12.9702 \\
\hline I3->D3 & $0.3848 *$ & 0.3784 & 0.0613 & 0.0613 & 6.2721 \\
\hline I3->Z & $0.0852 *$ & 0.0837 & 0.0103 & 0.0103 & 8.2601 \\
\hline I4->D4 & 0.8094* & 0.8017 & 0.0319 & 0.0319 & 25.4061 \\
\hline I4->Z & $0.2587^{*}$ & 0.2558 & 0.0165 & 0.0165 & 15.6813 \\
\hline O1->D1 & $0.3471 *$ & 0.3283 & 0.0743 & 0.0743 & 4.6702 \\
\hline $\mathrm{O} 1->\mathrm{Z}$ & $0.0655^{*}$ & 0.0612 & 0.0159 & 0.0159 & 4.1196 \\
\hline $\mathrm{O} 2->\mathrm{D} 2$ & $0.2184 *$ & 0.2154 & 0.0339 & 0.0339 & 6.4506 \\
\hline $\mathrm{O} 2->\mathrm{Z}$ & $0.0850^{*}$ & 0.0833 & 0.0120 & 0.0120 & 7.0663 \\
\hline O3->D3 & $0.1473^{*}$ & 0.1561 & 0.0445 & 0.0445 & 3.3058 \\
\hline $\mathrm{O} 3->\mathrm{Z}$ & $0.0326^{*}$ & 0.0352 & 0.0119 & 0.0119 & 2.7488 \\
\hline O4->D4 & $0.1791 *$ & 0.1780 & 0.0301 & 0.0301 & 5.9485 \\
\hline O4->Z & $0.0572 *$ & 0.0569 & 0.0104 & 0.0104 & 5.5123 \\
\hline P1->D1 & $0.0911 *$ & 0.1040 & 0.0327 & 0.0327 & 2.7849 \\
\hline $\mathrm{P} 1->\mathrm{D} 2$ & $0.0521 *$ & 0.0591 & 0.0194 & 0.0194 & 2.6884 \\
\hline P1->D3 & $0.0437 \sim$ & 0.0594 & 0.0239 & 0.0239 & 1.8255 \\
\hline P1->D4 & $0.0629 *$ & 0.0694 & 0.0211 & 0.0211 & 2.9832 \\
\hline$P 1->Z$ & $0.0673^{*}$ & 0.0773 & 0.0234 & 0.0234 & 2.8785 \\
\hline
\end{tabular}

$*, \sim$ indicates significant at $1 \%$ and $10 \%$ significance level, respectively

Table 2: Path Coefficient and Total Effect of Revised Path Modeling

\begin{tabular}{lccccc}
\hline Path Direction & $\begin{array}{c}\text { Original } \\
\text { Sample (O) }\end{array}$ & $\begin{array}{c}\text { Sample } \\
\text { Mean (M) }\end{array}$ & $\begin{array}{c}\text { Standard } \\
\text { Deviation } \\
\text { (STDEV) }\end{array}$ & $\begin{array}{c}\text { Standard } \\
\text { Error } \\
\text { (STERR) }\end{array}$ & $\begin{array}{c}\text { T Statistics } \\
\text { (|O/STERR|) }\end{array}$ \\
\hline C1 -> D1 & $0.3634^{*}$ & 0.3565 & 0.0348 & 0.0348 & 10.4297 \\
C1 -> Z & $0.0681^{*}$ & 0.0662 & 0.0082 & 0.0082 & 8.2951 \\
C2 -> D2 & $0.0933^{*}$ & 0.0904 & 0.0129 & 0.0129 & 7.2298 \\
C2 -> Z & $0.0363^{*}$ & 0.0349 & 0.0044 & 0.0044 & 8.2605 \\
C3 -> D3 & $0.7032^{*}$ & 0.6814 & 0.0429 & 0.0429 & 16.3807 \\
C3 -> Z & $0.1562^{*}$ & 0.1536 & 0.0196 & 0.0196 & 7.9698 \\
C4 -> D4 & $0.1730^{*}$ & 0.1694 & 0.0198 & 0.0198 & 8.7372 \\
C4 -> Z & $0.0553^{*}$ & 0.0539 & 0.0064 & 0.0064 & 8.6041 \\
D1 -> Z & $0.1875^{*}$ & 0.1855 & 0.0127 & 0.0127 & 14.7526 \\
D2 -> Z & $0.3891^{*}$ & 0.3871 & 0.0218 & 0.0218 & 17.8745 \\
D3 -> Z & $0.2221^{*}$ & 0.2248 & 0.0196 & 0.0196 & 11.3313 \\
D4 -> Z & $0.3194^{*}$ & 0.3185 & 0.0168 & 0.0168 & 19.0326 \\
I1 -> D1 & $0.6855^{*}$ & 0.6792 & 0.0548 & 0.0548 & 12.5047 \\
I1 -> Z & $0.1285^{*}$ & 0.1257 & 0.0100 & 0.0100 & 12.8418 \\
I2 -> D2 & $0.8336^{*}$ & 0.8282 & 0.0298 & 0.0298 & 28.0180 \\
I2 -> Z & $0.3244^{*}$ & 0.3208 & 0.0243 & 0.0243 & 13.3659 \\
I3 -> D3 & $0.3889^{*}$ & 0.3830 & 0.0611 & 0.0611 & 6.3612 \\
I3 -> Z & $0.0864^{*}$ & 0.0853 & 0.0099 & 0.0099 & 8.7372 \\
I4 -> D4 & $0.8105^{*}$ & 0.8049 & 0.0318 & 0.0318 & 25.4967 \\
I4 -> Z & $0.2589^{*}$ & 0.2563 & 0.0163 & 0.0163 & 15.9064 \\
O1 -> D1 & $0.3428^{*}$ & 0.3282 & 0.0708 & 0.0708 & 4.8395 \\
O1 -> Z & $0.0643^{*}$ & 0.0613 & 0.0156 & 0.0156 & 4.1207 \\
O2 -> D2 & $0.2176^{*}$ & 0.2149 & 0.0336 & 0.0336 & 6.4749 \\
O2 -> Z & $0.0847^{*}$ & 0.0829 & 0.0119 & 0.0119 & 7.1275 \\
O3 -> D3 & $0.1486^{*}$ & 0.1603 & 0.0452 & 0.0452 & 3.2912 \\
& & & & \\
\hline
\end{tabular}




\begin{tabular}{llllll} 
O3 $>$ > Z & $0.0330^{*}$ & 0.0365 & 0.0127 & 0.0127 & 2.6085 \\
O4 -> D4 & $0.1784^{*}$ & 0.1782 & 0.0303 & 0.0303 & 5.8839 \\
O4 -> Z & $0.0570^{*}$ & 0.0568 & 0.0104 & 0.0104 & 5.4567 \\
P1 - D1 & 0.0880 & 0.0697 & 0.0682 & 0.0682 & 1.2911 \\
P1 -> D2 & 0.0479 & 0.0382 & 0.0372 & 0.0372 & 1.2899 \\
P1 - D 3 & 0.0416 & 0.0380 & 0.0389 & 0.0389 & 1.0685 \\
P1 -> D4 & 0.0626 & 0.0480 & 0.0457 & 0.0457 & 1.3676 \\
P1 - Z & 0.0644 & 0.0514 & 0.0491 & 0.0491 & 1.3117 \\
\hline
\end{tabular}

* indicates significant at $1 \%$ significance level

Another issue of testing validity is to examine the degree of multicollinearity in the formative indicators. Previous studies recommended eliminating an indicator to relax multicollinearity problems if this indicator's outer weight was not significant and the remaining indicators could sufficiently capture the domain of the construct under consideration. Further, it was also suggested to group the indicators into two or more distinct constructs to avoid the problem. This initial path model already grouped the indicators into several construct while running the $2^{\text {nd }}$ stage formative model. It was also found that the remaining indicators were not enough to capture the domain of the relevant construct. Thus, overall resilience construct (P1) became insignificant in the revised model. Therefore, this study could assume there was no multicollinearity problem in the initial model.

In the initial path model, all of the constructs have been found significant to determine food insecurity (Table 1; Figure 2). Thus, direct and indirect factors of climate change and other non-climatic general factors have significant positive impacts on all the four dimensions of household food security. Among the four dimensions of household food security, the impact of food accessibility (D2) is the highest to determine household food security (Z1). The data indicate that a 100 points change in food accessibility will bring 38.91 points change in the household food security (Table 1; Figure 2). Similarly, a 100 points change in food availability (D1), food utilization/consumption (D3), and food system stability (D4) will bring 18.83, 2.15 and 32 points change in the household food security, respectively. 


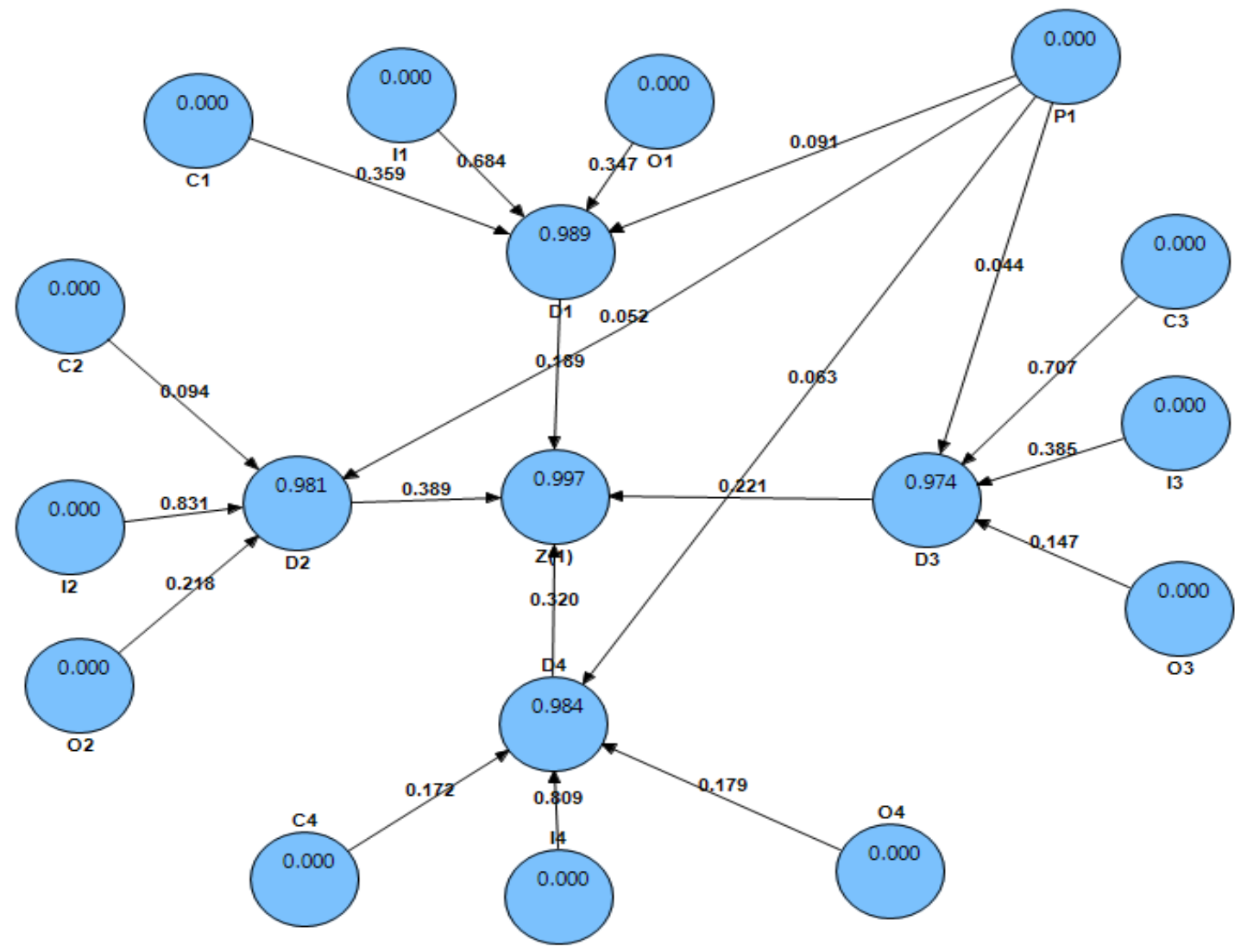

Figure 2: Smart PLS Path Modeling Diagram (Second Order Model)

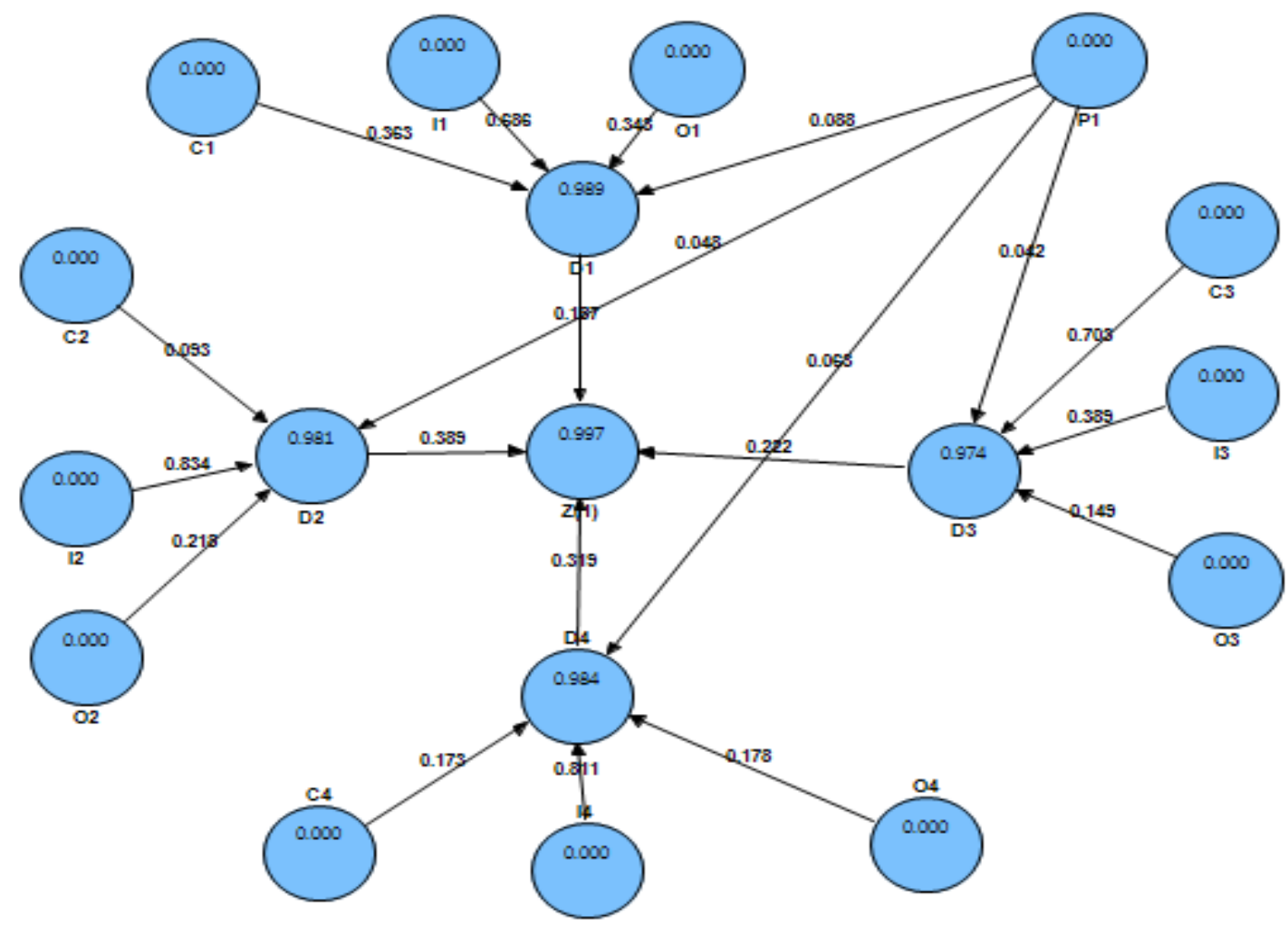

Figure 3: Smart PLS Path Modeling Diagram (Revised Second Order Model) 
In the case of the individual dimensions of household food security, while measuring the dimension of food availability (D1), the coefficient of indirect impacts of climatic change (I1) is higher than the direct impact of climatic change (C1), resilience impacts (P1) and nonclimatic general factors impacts (O1) (Table 1; Figure 2). A 100 points change in the indirect impacts of climate change (I1), direct impacts of climatic change (C1), resilience impacts (P1) and non-climatic general factors impacts (O1) will bring 68.4, 35.9, 9.1, and 34.7 points, change in the dimension of household food availability (D1) respectively.

In the case of measuring the dimension of food accessibility (D2), the coefficient of indirect impacts of climatic change (I2) is higher than the direct impact of climatic change (C2), resilience impacts (P2) and non-climatic general factors impacts (O2) (Table 1; Figure 2). A 100 points change in the indirect impacts of climate change (I2), direct impacts of climatic change $(\mathrm{C} 2)$, resilience impacts $(\mathrm{P} 2)$ and non-climatic/general factors impacts $(\mathrm{O} 2)$ will bring $83.1,9.4,5.2$, and 21.8 points, change in the dimension of household food accessibility (D2) respectively.

In the case of measuring the dimension of food utilization/consumption (D3), the coefficient of direct impact of climatic change (C3) is higher than the indirect impacts of climatic change (I3), resilience impacts (P3) and non-climatic/general factors impacts (O3) (Table 1; Figure 2). A 100 points change in the direct impacts of climatic change (C3), indirect impacts of climate change (I3), resilience impacts (P3) and non-climatic general factors impacts (O3) will bring 70.7, 38.5, 4.4, and 14.7 points change in the dimension of household food utilization/consumption (D3) respectively.

In the case of measuring the dimension of food system stability (D4), the coefficient of indirect impacts of climatic change (I4) is higher than the direct impact of climatic change (C4), resilience impacts (P4) and non-climatic/general factors impacts (O4) (Table 1; Figure 2). A 100 points change in the indirect impacts of climate change (I4), direct impacts of climatic change $(\mathrm{C} 4)$, resilience impacts $(\mathrm{P} 4)$ and non-climatic general factors impacts $(\mathrm{O} 4)$ will bring 80.9, 17.2, 6.3, and 17.9 points, change in the dimension of household food system stability (D4) respectively. Overall, the direct or indirect impacts of climatic factors contribute more than the resilience or other non-climatic general factors for determining household food security.

\section{Conclusions and Recommendations}

The study finds that the constructs of direct and indirect impacts of climate change, resilience factors, and other non-climatic general factors have statistically significant positive impacts on all the four dimensions of household food security. Among the four dimensions of household food security, it is found that the impact of food accessibility (D2) is the highest to determine the household food security (Z1).

Climate change is one of the major potential threats for household food security in Malaysia. Therefore, to ensure sustainable household food security in Malaysia, design of food security programs must integrate climatic change into the picture, and food security approaches must recognize climate change as an important driver. This integration also increases household capacity to adapt to climatic change. At the same time, climate change adaptation approaches and strategies to reduce vulnerability to climate change also increases household food security.

Prioritization of needs for investment targeted at increasing food security adaptation to climate change is important for Malaysia. Climate change adaptations are concentrated on improving the potential of people, especially the most vulnerable groups, toward adapting to climate changes. This involves support for livelihoods that are climate-resilient, reduction of disaster risk, advocacy, empowerment, and social mobilization to curb the underlying causes 
of vulnerability. To adequately deal with the effects of climate change on food security, plans have to begin with a good analysis of the groups that are already particularly marginal at present. They are the most affected by climate change often, and they have very limited capacities for coping.

Therefore, climate change affects groups that have always been at risk with food insecurity, and it also affects new groups who become vulnerable to regional weather changing conditions. Most vulnerable groups already practice some form of risk management, but their capability to adapt to changes in the climate is often limited due to their extremely restricted coping potential. Therefore, the climate change adaptation techniques and food security should empower the groups that socially exclude to lower their vulnerability and improve their resilience. Adaptation programs must address food security as a main challenge faced by the populations that are vulnerable to the climate, while food security plans in most cases offer people's capability to adapt to changes in climate, specifically when climate change is taken explicitly into consideration in the programs design. They are approaches that are mutually supportive. In vulnerable places where people are affected by both food insecurity and climate change effects, increasingly adopting an integrated method is the best. This integration should take place around account risk reduction, the resilient livelihoods, and the underlying causes of food insecurity.

The mitigation options are important when planning for long term programs. In the long run, the people who are vulnerable should be empowered and encouraged to adapt to climate change by developing resilience via investments in health, social protection, education, and such other methods. Monitoring weather extremes and design strategies for disaster preparation are also very important. Given these effects and the resources needed to adapt them, resources that realize the Millennium Development Goals (MDGs) might be integrated as well. Further, the private sector should advocate mitigation methods like energy efficiency, renewable energy, developments of infrastructure which include dams, floodresistant storage facilities, cyclone shelters, and techniques for lowering water loss in distribution systems, etc.

Finally, local, national, and regional governments and their resources need to be mobilized systematically and cohesively to enhance capacity building in communities that are particularly at high risk with regard to climatic changes and food insecurity.

\section{Acknowledgement}

We are thankful to Ministry of Science, Technology and Environment of the Government of Malaysia for generously funding the research, under the Research University Grant Project UKM-GUP-PI-08-34-081 and FRGS/1/2012/SS07/UKM/01/3.

\section{Appendix}

Definition of the variables:

$\mathrm{Z}=$ Household food security status

$\mathrm{D}_{1}=$ Food availability

$\mathrm{D}_{2}=$ Food accessibility

$\mathrm{D}_{3}=$ Food utilization/consumption

$\mathrm{D}_{4}=$ Food system stability

$\mathrm{C}_{1 \ldots 4}=$ Factors of household food security that directly impacted by climatic change

$\mathrm{I}_{1 \ldots .}=$ Factors of household food security that indirectly impacted by climatic change

$\mathrm{O}_{1 \ldots 4}=$ Non-climatic/general factors affecting dimension of household food security

$\mathrm{P}=$ Resilience factors affecting dimension of household food security

$\mathrm{X} 1=$ Education level, where illiterate $=1$, primary $=2$, secondary $=3$, certificate $=4$

$\mathrm{X} 2$ = Number of school going children, where no school going children $=1,1-2$ children $=2,3$ children $=3,4-5$ children $=4$, more than 5 children $=5$

$\mathrm{X} 3$ = Household poverty/economic status, where marginally non-poor=1, recently marginally non-poor=2, poor=3, hard core poor $=4$ 
$\mathrm{X} 4=$ Spouse doing job, where yes $=1$, no $=0$

$\mathrm{X} 5=$ Head of household having supplementary job, where yes $=1$, no $=0$

X6 Earning Ratio (Earning Family Member / Total Family Member) is coded in 1-5 scale based on equal value for every $20 \%$ ratio value, where $0-20 \%, 21-40 \%, 41-60 \%, 6-80 \%$, and $81-100 \%$ are coded as 1,2 , $3,4,5$ respectively.

X7 Locality, where urban $=1$, rural $=0$

X8 Ownership of house, where yes $=1$, no $=0$

X9 Type of home, where wood made $=1$, mixed $=2$, brick $=3$

X10 Household having any transport for buying food, where yes $=1$, no $=0$

X11 Household buying bulk amount of food, where yes $=1$, no $=0$

X12 The effectiveness of current food distribution process in Malaysia, where very low $=1$, low $=2$, normal=3, high $=4$, very high $=5$

X13 Current road and transportation facility for food distribution process in Malaysia, where very low=1, low $=2$, normal $=3$, high $=4$, very high $=5$

X14 Availability of expected food in the local market, where very low $=1$, low $=2$, normal=3, high $=4$, very high $=5$

X15 Sufficiency of expected food in the local market, where very low $=1$, low $=2$, normal $=3$, high $=4$, very high $=5$

X16 Household having any savings, where yes $=1$, no $=0$

X17 Current prices of general food items, where very low $=1$, low $=2$, normal $=3$, high $=4$, very high $=5$

X18 Current difference between rural and city food prices, where very low $=1$, low $=2$, normal $=3$, high $=4$, very high $=5$

X19 High prices of food cause household food shortage, where very low=1, low=2, normal=3, high=4, very high $=5$

X20 Current level of household income, where very low $=1$, low $=2$, normal $=3$, high $=4$, very high $=5$

X21 Low level of income cause household food shortage, where very low $=1$, low $=2$, normal $=3$, high $=4$, very high $=5$

X22 Ready budget arrangement to buy food anytime, where very low $=1$, low $=2$, normal $=3$, high $=4$, very high $=5$

X23 Availability of discount or offer on food price in the local market, where very low $=1$, low $=2$, normal=3, high $=4$, very high $=5$

X24 The effectiveness of current food distribution process in Malaysia, where very low=1, low=2, normal=3, high $=4$, very high $=5$

X25 Dependency on common resources for cattle or livestock feeding, where very low $=1$, low $=2$, normal=3, high $=4$, very high $=5$

X26 Current competition among people for common resources, where very low=1, low=2, normal=3, high=4, very high $=5$

X27 Current expenditure for feeding and medicine of cattle and livestock, where very low $=1$, low $=2$, normal $=3$, high $=4$, very high $=5$

X28 Household having neat and clean kitchen and dining place, where yes $=1$, no $=0$

X29 Household having a hygienic sanitation facility, where strongly disagree $=1$, disagree $=2$, not sure $=3$, agree $=4$, strongly agree $=5$

X30 Household maintaining waste properly, where strongly disagree $=1$, disagree $=2$, not sure $=3$, agree $=4$, strongly agree $=5$

X31 Household having knowledge about maintaining nutritious and hygienic way of cooking and washing food, where strongly disagree $=1$, disagree $=2$, not sure $=3$, agree $=4$, strongly agree $=5$

X32 Household having knowledge about taking precaution against dengue, malaria, etc., where strongly disagree $=1$, disagree $=2$, not sure $=3$, agree $=4$, strongly agree $=5$

X33 Difference between rural and city food quality, where very low $=1$, low $=2$, normal $=3$, high $=4$, very high $=5$

X34 Food quality or nutrition level in local market, where very low $=1$, low $=2$, normal $=3$, high $=4$, very high $=5$

Food quality on food safety in local market, where very low $=1$, low $=2$, normal $=3$, high $=4$, very high $=5$ Quality of drinking water, where very low $=1$, low $=2$, normal $=3$, high $=4$, very high $=5$

Stability of food price, where very low $=1$, low $=2$, normal $=3$, high $=4$, very high $=5$

Price variation among shops in the local market, where very low $=1$, low $=2$, normal $=3$, high $=4$, very high $=5$

X39 Access of quick credit to buy food, where very low $=1$, low $=2$, normal $=3$, high $=4$, very high $=5$

X40 Stability of food supply, where very low $=1$, low $=2$, normal=3, high $=4$, very high $=5$

X41 Unavailability of food in market leading food shortage, where very low $=1$, low $=2$, normal $=3$, high $=4$, very high $=5$

X42 Agencies supports for household food security, where very low=1, low=2, normal=3, high=4, very high $=5$

X43 Current level of incidences of mosquitos, insects, pest, etc., where very low=1, low=2, normal=3, high $=4$, very high $=5$

X44 Current level of incidences of disease like dengue, malaria, heat stretch, cold, skin disease, etc., where very low $=1$, low $=2$, normal $=3$, high $=4$, very high $=5$ 

issues, where very low $=1$, low $=2$, normal $=3$, high $=4$, very high $=5$

X47 Changes in the road and transportation facility for food distribution in Malaysia over last five years due to climatic issues, where very low $=1$, low $=2$, normal $=3$, high $=4$, very high $=5$

X48 Changes in the availability of expected food in the local market over last five years due to climatic issues, where very low $=1$, low $=2$, normal $=3$, high $=4$, very high $=5$

X49 Changes in the sufficiency of expected food in the local market over last five years due to climatic issues, where very low $=1$, low $=2$, normal $=3$, high $=4$, very high $=5$

X50 Changes in the prices of general food items over last five years due to climatic issues, where very low $=1$, low $=2$, normal $=3$, high $=4$, very high $=5$

X51 Changes in the difference between rural and city food prices over last five years due to climatic issues, where very low $=1$, low $=2$, normal $=3$, high $=4$, very high $=5$

X52 Changes in the high prices leading household food shortage over last five years due to climatic issues, where very low $=1$, low $=2$, normal $=3$, high $=4$, very high $=5$

X53 Changes in the level of household income over last five years due to climatic issues, where very low $=1$, low $=2$, normal $=3$, high $=4$, very high $=5$

X54 Changes in the low level of income leading food shortage over last five years due to climatic issues, where very low $=1$, low $=2$, normal $=3$, high $=4$, very high $=5$

X55 Changes in the ready budget arrangement to buy food anytime over last five years due to climatic issues, where very low $=1$, low $=2$, normal $=3$, high $=4$, very high $=5$

X56 Changes in the availability of discount or offer on food price in the local market over last five years due to climatic issues, where very low $=1$, low $=2$, normal $=3$, high $=4$, very high $=5$

X57 Changes in the efficiency of household food acquisition or collection system over last five years due to climatic issues, where very low $=1$, low $=2$, normal $=3$, high $=4$, very high $=5$

X58 Changes in the dependency on common resources for cattle or livestock feeding over last five years due to climatic issues, where very low $=1$, low $=2$, normal $=3$, high $=4$, very high $=5$

X59 Changes in the competition among people for common resources over last five years due to climatic issues, where very low $=1$, low $=2$, normal $=3$, high $=4$, very high $=5$

X60 Changes in the expenditure for feeding and medicine of cattle and livestock over last five years due to climatic issues, where very low $=1$, low $=2$, normal $=3$, high $=4$, very high $=5$

X61 Changes in the difference between rural and city food quality over last five years due to climatic issues, where very low $=1$, low $=2$, normal $=3$, high $=4$, very high $=5$

X62 Changes in the food quality or nutrition level in local market over last five years due to climatic issues, where very low $=1$, low $=2$, normal $=3$, high $=4$, very high $=5$

X63 Changes in the food quality on food safety in local market over last five years due to climatic issues, where very low $=1$, low $=2$, normal $=3$, high $=4$, very high $=5$

X64 Changes in the quality of drinking water over last five years due to climatic issues, where very low $=1$, low $=2$, normal $=3$, high $=4$, very high $=5$

X65 Changes in the stability of food price over last five years due to climatic issues, where very low=1, low $=2$, normal $=3$, high $=4$, very high $=5$

X66 Changes in the price variation among shops in the local market over last five years due to climatic issues, where very low $=1$, low $=2$, normal $=3$, high $=4$, very high $=5$

X67 Changes in the access of quick credit to buy food over last five years due to climatic issues, where very low $=1$, low $=2$, normal $=3$, high $=4$, very high $=5$

X68 Changes in the stability of food supply over last five years due to climatic issues, where very low=1, low $=2$, normal $=3$, high $=4$, very high $=5$

X69 Changes in the unavailability of food in market leading food shortage over last five years due to climatic issues, where very low $=1$, low $=2$, normal $=3$, high $=4$, very high $=5$

X70 Changes in the agencies supports for household food security over last five years due to climatic issues, where very low $=1$, low $=2$, normal $=3$, high $=4$, very high $=5$

X71 Changes in the incidences of mosquitos, insects, pest, etc. over last five years due to climatic issues, where very low $=1$, low $=2$, normal $=3$, high $=4$, very high $=5$

X72 Changes in the incidences of disease like dengue, malaria, heat stretch, cold, skin disease, etc. over last five years due to climatic issues, where very low $=1, \operatorname{low}=2$, normal $=3$, high $=4$, very high $=5$

X73 Climatic issues affect household food collection system, where strongly disagree $=1$, disagree $=2$, not sure $=3$, agree $=4$, strongly agree $=5$

X74 Climatic issues affect household food storage system (e.g. Refrigerator, packaging, etc.), where strongly disagree $=1$, disagree $=2$, not sure $=3$, agree $=4$, strongly agree $=5$

X75 Climatic issues affect household food storage process (e.g. Dry, salty, oily, etc.), where strongly disagree $=1$, disagree $=2$, not sure $=3$, agree $=4$, strongly agree $=5$

X76 Climatic issues and related disease reduces income, where yes $=1$, no $=0$

X77 Climatic issues increase household food storage cost, where strongly disagree $=1$, disagree $=2$, not sure $=3$, agree $=4$, strongly agree $=5$

X78 Climatic issues affect household usage or utilization of land, where strongly disagree $=1$, disagree $=2$, not sure $=3$, agree $=4$, strongly agree $=5$ 
X79 Climatic issues reduce normal food test, where strongly disagree $=1$, disagree $=2$, not sure $=3$, agree $=4$, strongly agree $=5$

X80 Climatic issues reduce food longevity, where strongly disagree $=1$, disagree $=2$, not sure $=3$, agree $=4$, strongly agree $=5$

X81 Climatic issues affect household food choice and habit, where strongly disagree $=1$, disagree $=2$, not sure $=3$, agree $=4$, strongly agree $=5$

X82 Climatic issues affect household cooking system (e.g. Cooking by gas or stove not by woods), where strongly disagree $=1$, disagree $=2$, not sure $=3$, agree $=4$, strongly agree $=5$

X83 Climatic issues affect cooking time and amount (e.g. large amount of cooking together or several time cooking for hot food or several times heating for not rotating), where strongly disagree $=1$, disagree $=2$, not sure $=3$, agree $=4$, strongly agree $=5$

X84 Climatic issues cause to eat outside or buy ready food from outside, where strongly disagree=1, disagree $=2$, not sure $=3$, agree $=4$, strongly agree $=5$

X85 Climatic issues affect the environment and cleanness of kitchen, where strongly disagree $=1$, disagree $=2$, not sure $=3$, agree $=4$, strongly agree $=5$

X86 Climatic issues affect household waste management, where strongly disagree $=1$, disagree $=2$, not sure $=3$, agree $=4$, strongly agree $=5$

X87 Climatic issues affect home sanitation system, where strongly disagree $=1$, disagree $=2$, not sure $=3$, agree $=4$, strongly agree $=5$

X88 Climatic issues hamper food aid services and food supports program, where strongly disagree=1, disagree $=2$, not sure $=3$, agree $=4$, strongly agree $=5$

X89 Climatic issues increase short term food prices, where strongly disagree $=1$, disagree $=2$, not sure $=3$, agree $=4$, strongly agree $=5$

X90 Climatic issues cause to increase food price in restaurant, where strongly disagree $=1$, disagree $=2$, not sure $=3$, agree $=4$, strongly agree $=5$

\section{References}

Abdulai, A. \& CroleRees, A. 2001. Constraints to income diversification strategies: Evidence from Southern Mali. Food Policy 26(4): 437-452.

Alam, M.M., Talib, B., Siwar, C. \& Mohd Ekhwan, T. 2014. Impacts of Climatic Changes on Paddy Production in Malaysia: Micro Study on IADA at North West Selangor, Research Journal of Environmental and Earth Sciences 6(5): 251-258.

Ali, R. \& Ali, A.K. 2009. Estimating the Prospective Impacts of Global Warming on Malaysian Agriculture. Proceeding of 2nd National Conference on Agro-Environment 2009, MARDI, Johor Bahru, Malaysia, Mar 24-26.

Alinovi, L., D’Errico, M., Mane, E. \& Romano, D. 2010. Livelihoods Strategies and Household Resilience to Food Insecurity: An Empirical Analysis to Kenya. Presented in the conference on Promoting Resilience through Social Protection in Sub-Saharan Africa, European Report of Development in Dakar, Senegal, 28-30 Jun.

Alinovi, L., Mane, E. \& Romano, D. 2009. Measuring Household Resilience to Food Insecurity: Application to Palestinian Households, Working Paper, EC-FAO Food Security Programme, Rome.

Baker, J.T. \& Allen, Jr. L.H. 1993. Contrasting crop species responses to $\mathrm{CO}_{2}$ and temperature: rice, soybean and citrus. Vegetatio 104/105: 239-260.

Bollen, K. \& Lennox, R. 1991. Conventional wisdom on measurement: A structural equation perspective, Psychological Bulletin 110(2): 305-314.

Cenfetelli, R.T. \& Bassellier, G. 2009. Interpretation of Formative Measurement in Information Systems Research, MIS Quarterly 33(4): 689-708.

Checkley, W., Epstein, L.D., Gilman, R.H., Figueroa, D., Cama, R.I., Patz, J.A. \& Black, R.E. 2000. Effects of El Niño and Ambient Temperature on Hospital Admissions for Diarrhoeal Diseases in Peruvian Children. The Lancet 355 (9202): 442-450.

Chin, W., 1998. The partial least squares approach to structural equation modeling. In Marcoulides, G. (ed.). Modern methods for business research. pp. 295-336. Mahwah, NJ: Lawrence Erlbaum Associates. 
Cline, W.R. 2007. Global Warming and Agriculture: Impact Estimates by Country. Washington, DC: Center for Global Development and Peterson Institute for international Economics.

Cristofar S.P. \& Basiotis P.P. 1992. Dietary intakes and selected characteristics of women ages 19-50 years and their children ages 1-5 years by reported perception of food sufficiency. Journal of Nutrition Education 24(2):53-58.

Cruz, R.V., Harasawa, H., Lal, M., Wu, S., Anokhin, Y., Punsalmaa, B., Honda, Y., Jafari, M., Li, C. \& Huu Ninh, N. 2007. Asia. In: Parry, M.L., Canziani, O.F., Palutikof, J.P., van der Linden, P.J. \& Hanson, C.E. (eds.) Climate Change 2007: Impacts, Adaptation and Vulnerability. Contribution of Working Group II to the Fourth Assessment Report of the Intergovernmental Panel on Climate Change, Cambridge University Press, Cambridge, UK, pp. 469-506.

Curb Global Warming. 2007. Malaysia leads the world in greenhouse gas emission growth rate. (online) http://curbglobalwarmingblog.blogspot.com/2007/11/malaysia-leadsworld-in-greenhouse-gas.html (5 Jul 2012).

Diamantopoulos, A. \& Siguaw, J.A. 2006. Formative vs. Reflective Indicators Measure Development: Does the Choice of Indicators. British Journal of Management 13(4), 263-282.

Diamantopoulos, A. 2006. The error term in formative measurement models: interpretation and modelingng implications. Journal of Modeling in Management 1(1): 7-17.

ECA. 2004. Land Tenure Systems and their Impacts on Food Security and Sustainable Development in Africa. Addis Ababa: ECA.

Edwards, J.R. \& Bagozzi, R. P. 2000. On the Nature and Direction of Relationships Between Constructs and Measures, Psychological Methods 5(2), 155-174.

Energy Information Administration (EIA) 2005. International energy annual 2005 - CO2 world carbon dioxide emissions from the consumption of coal, 1980-2006 (Million Metric Tons of Carbon Dioxide). Washington, DC: Government of US.

FAO. 2007. Food Outlook November 2007: High prices and volatility in agricultural commodities. Rome: FAO.

FAO. 2008. Climate Change and Food Security: A Framework Document, FAO interdepartmental working group on climate change, Rome: FAO.

Frankenberger, T. 1992. Indicators and Data Collection Methods for Assessing Household Food Security. In: Simon, M. \& Frankeberger, T.R. (eds.) Household Food Security: Concepts, Indicators, and Measurements: a technical Review, pp. 74-134. IFAD \& UNICEF, Rome \& New York.

IPCC. 2007. Climate change 2007- Impacts, adaptation and vulnerability. Cambridge. UK. Cambridge University Press.

Iram, U. \& Butt, M.S. 2004. Determinants of household food security: an empirical analysis for Pakistan. International Journal of Social Economics 31(8):735-766.

Kovats, R.S., Edwards, S. Hajat, S. Armstrong, B., Ebi, K.L. \& Menne, B. 2004. The Effect of Temperature on Food Poisoning: Time Series Analysis in 10 European Countries. Epidemiology and Infection 132 (3): 443-453.

Kundzewicz, Z.W., Mata, L.J., Arnell, N.W., Döll, P., Kabat, P., Jiménez, B., Miller, K.A., Oki, T., Sen, Z., \& Shiklomanov, I.A. 2007. Freshwater resources and their management. In: Parry, M.L., Canziani, O.F., Palutikof, J.P., van der Linden, P.J. \& Hanson, C.E. (eds.) Climate Change 2007: Impacts, Adaptation and Vulnerability. Contribution of Working Group II to the Fourth Assessment Report of the Intergovernmental Panel on Climate Change, Cambridge University Press, Cambridge, UK, pp.173-210. 
Lovendal, C.R. \& Knowles, M. 2006. Tomorrow's Hunger: A Framework for Analysing Vulnerability to Food Security, UNU- WIDER, Research Paper No. 2006/119, Helsinki.

Mimura, N., Nurse, L., McLean, R.F., Agard, J., Briguglio, L., Lefale, P., Payet, R. \& Sem, G. 2007. Small Islands. In: Parry, M.L., Canziani, O.F., Palutikof, J.P., van der Linden, P.J. \& Hanson, C.E. (eds.) Climate Change 2007: Impacts, Adaptation and Vulnerability. Contribution of Working Group II to the Fourth Assessment Report of the Intergovernmental Panel on Climate Change, Cambridge University Press, Cambridge, UK, pp. 687-716.

MOSTE, 2001. National Response Strategies to Climate Change. Ministry of Science, Technology and the Environment, Putrajaya, Malaysia.

NAHRIM. 2006. Final Report: Study of the Impact of Climate Change on the hydrologic Regime and Water Resources of Peninsular Malaysia, National Hydraulic Research Institute of Malaysia (NAHRIM) and California Hydrologic Research Laboratory (CHRL), Seri Kembangan, Malaysia..

Nyariki, D.M. \& Wiggins, S. 1997. Household Food insecurity in Sub-Saharan Africa: Lesson from Kenya. British food journal 99(7): 249-262.

Olson, C.M., Rauschenbach, B.S., Frongillo, E.A. \& Kendall, A. 1997. Factors contributing to household food insecurity in rural upstate New York. Family Economics and Nutrition Review 10(2): 2-17.

Petter, S., Straub, D. \& Rai, A. 2007. Specifying formative constructs in information systems research, MIS Quarterly 31(4): 623-656.

Rose, D., Basiotis, P.P. \& Klein, B.W. 1995. Improving federal efforts to assess hunger and food insecurity. Food Review 18(1): 18-23.

Singh, S., Amartalingam, R., Wan Harun, W.S. \& Islam, M.T. 1996. Simulated impact of climate change on rice production in Peninsular Malaysia. Proceeding of National Conference on Climate Change. pp. 41-49, UPM, Malaysia.

Spirtes, P., Glymour, C. \& Scheines, R. 2000. Causation, prediction and search. MIT Press, Chicago, Michigan, USA.

Tashiro, T. \& Wardlaw, I.F. 1989. A comparison of the effect of high temperature on grain development in wheat and rice. Annals of Botany 64(1): 59-65.

Thomsen, A. \& Metz, M. 1998. Implications of economic policy for food security: A training manual. Rome. FAO and the German Agency for Technical Cooperation (GTZ).

Tisdell, C. 1996. Economic indicators to assess the sustainability of conservation farming projects: An evaluation. Agriculture, Ecosystems and Environment 57(2): 117-131.

Von Braun, J. 2007. The World Food Situation: New Driving Forces and Required Actions. Food Policy Report. Washington, DC: IFPRI.

Zimmerman, M., DePaola, A., Bowers, J.C., Krantz, J.A., Nordstrom, J.L., Johnson, C.N. \& Grimes, D.J. 2007. Variability of Total and Pathogenic Vibrio Parahaemolyticus Densities in Northern Gulf of Mexico Water and Oysters. Applied and Environmental Microbiology 73 (23): 7589-7596.

\section{Further reading}

Alam, M.M., Morshed, G., Siwar, C. \& Murad, M.W. 2012. Initiatives and Challenges of Agricultural Crop Sector in ECER Development Projects in Malaysia, AmericanEurasian Journal of Agricultural \& Environmental Science 12(7): 922-931.

Alam, M.M., Siwar, C., Wahid, A.N.M. and Talib, B. 2016. Food Security and Low-Income Households in the Malaysian East Coast Economic Region: An Empirical Analysis. Review of Urban \& Regional Development Studies, 28(1): 2-15. 
Alam, M.M., Siwar, C., Jaafar, A.H. and Talib, B. 2016. Climatic Changes and Vulnerability of Household Food Availability in Malaysian East Coast Economic Region. Journal of Developing Areas. 50(5): 143-155.

Arshad, F.M., Shamsudin, M.N. \& Saleh, R. 1999. Food Security in Malaysia, Presented at Seminar on International Trade and Food Security. Asian Productivity Organisation, Tokyo, Feb.

FAO. 2003. Trade reforms and Food security: Conceptualizing the Linkages. Rome: FAO.

Fartahun, M., Berhane, Y., Wall, S., Byass, P., Hogberg, U. 2007. Women's involvement in household decision making and strengthening social capital are crucial factors for child survival in Ethiopia. Acta Paediatrica 96(4):582-589.

Hindin, M.J. 2006. Women's input in household decision and their nutritional status in three resource-constrained settings. Public Health Nutrition 9(4):485-493.

Myntti, C. 1993. Social determinants of child health in Yemen. Social Science \& Medicine 37(2):233-240.

Pfeiffer, J., Gloyd, S., Ramirez, L.L. 2001. Intra-household resource allocation and child growth in Mozambique: an ethnographic case-control study. Social Science \& Medicine 53(1):83-97.

Piaseu, N. 2006. Factors affecting food insecurity among urban poor in Thailand. South African Journal of Clinical Nutrition 18(2):156-160.

Workneh, N. 2006. Determinants of small farm household food security: evidence from south Wollo, Ethiopia. Ethiopian Journal of Development Research 28(1): 1-29. 